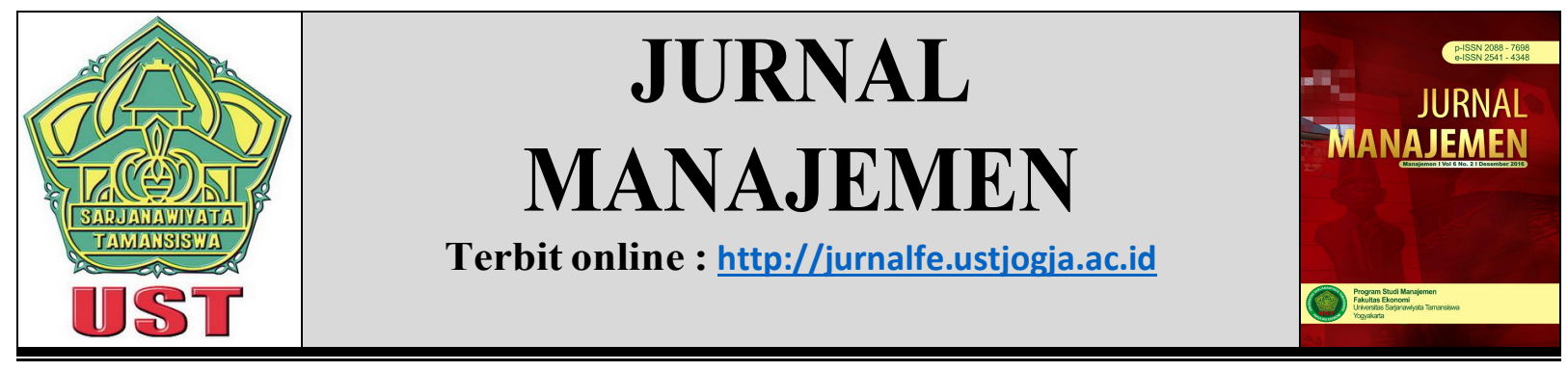

\title{
PENGARUH KECERDASAN EMOSIONAL, MOTIVASI EKSTRINSIK DAN BUDAYA ORGANISASI TERHADAP KREATIVITAS KARYAWAN PADA INDUSTRI KERAJINAN PERAK DI KOTAGEDE YOGYAKARTA
}

\author{
Anastasia Pungkasisari ${ }^{1}$ \\ Jajuk Herawati ${ }^{2}$ \\ 1)Alumni Jurusan Manajemen Fakultas Ekonomi Universitas Sarjanawiyata \\ Tamansiswa Yogyakarta \\ 2)Dosen Jurusan Manajemen Fakultas Ekonomi Universitas Universitas \\ Sarjanawiyata Tamansiswa Yogyakarta
}

Korespondensi: jajuk.herawati@yahoo.co.id

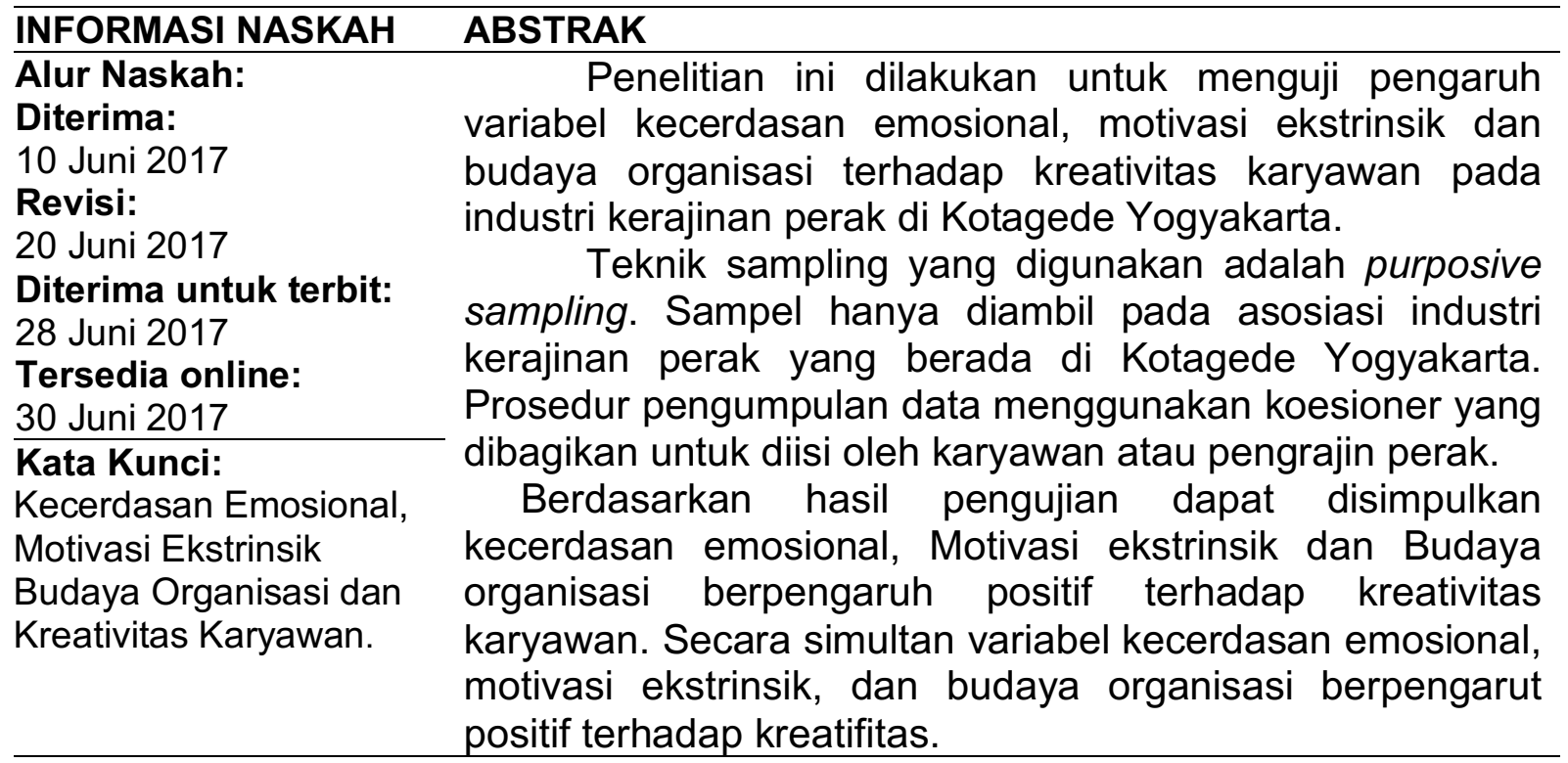

\section{PENDAHULUAN}

Kurangnya lapangan kerja yang terjadi memicu masyarakat untuk saling berkompetisi dalam menciptakan suatu usaha yang mampu menopang perekonomian mereka. Oleh karena itu, besar kontribusi yang diberikan dari pengusaha-pengusaha lokal. Banyaknya home industri 
atau industri kreatif, UKM dan Asosiasi Penggrajin sangat membantu dalam meningkatkan perekonomian di Indonesia. Masyarakat perlu mengembangkan kreatifitas mereka melalui industri-industri kerajinan atau ekonomi kreatif yang mereka ciptakan.

Industri kreatif saat ini didominasi oleh perusahaan-perusahaan yang tergolong skala menengah, dengan modal finansial tidak terlalu besar tetapi memerlukan dukungan keahlian, ketrampilan, serta kreativitas sumber daya manusianya. Dengan demikian, dipandang dari aspek mikro perusahaan, salah satu faktor penting pendukung keberhasilan industri kreatif salah satunya adalah kreativitas karyawan. (Herawati., et al,. 2015). Dengan adanya perkembangan zaman tentunya perusahaan maupun industri kreatif semakin berkembang dan semakin banyak persaingan yang terjadi. Untuk dapat bertahan sampai saat ini, para pengusaha dituntut untuk terus berkembang dengan kreativitas dan ide-ide baru dalam mempertahankan usaha yang dimiliki.

Beberapa karakteristik individu yang penentu kreativitas tersebut antara lain: kecerdasan, sifat kepribadian, dan keahlian. Lingkungan kreatif berkaitan dengan faktor-faktor lingkungan yang mendorong munculnya perilaku kreatif. Lingkungan kreatif tersebut meliputi: motivasi, penghargaan dan pengakuan dari pimpinan, kebebasan, pemberdayaan, budaya, kepemimpinan, dan pada situasi tertentu keragaman dalam kelompok kerja juga dapat memicu kreativitas.

Adapun faktor dominan yang mempengaruhi kreativitas seseorang diantaranya adalah kecerdasan emosional. Menurut Young (dalam Nawawi, 2006) kecerdasan emosional seseorang terdiri atas lima dimensi, yaitu: (1) kesadaran diri (self monitoring/self awareness), (2) mampu mengatur diri sendiri atau mengelola emosi diri (self regulation/managing emotion), (3) mampu memotivasi diri (self motivation), (4) empati dan mampu memahami perasaan orang lain, dan (5) ketrampilan sosial/menjaga hubungan sosial (social skill). Dimensi kecerdasan emosional tersebut identik dengan dimensi kecerdasan emosional yang digunakan oleh Gardner (dalam Luthans, 2006). Selain itu masih ada faktor lain yaitu motivasi ekstrinsik, merupakan motivasi yang ditimbulkan oleh faktor eksternal seseorang. Dengan demikian motivasi ekstrinsik tersebut dipicu oleh faktor yang berasal dari luar diri karyawan seperti kebijakan manajemen, pelaksanaan kebijakan perusahaan, supervisi oleh atasan, kondisi kerja, hubungan dengan rekan kerja, sistem upah atau gaji yang ditetapkan perusahaan. dan budaya organisasi sebagai sebuah corak asumsi-asumsi dasar, yang ditemukan atau dikembangkan oleh sebuah kelompok tertentu untuk belajar mengatasi problem-problem kelompok dan adaptasi eksternal dan integrasi internal, yang telah bekerja dengan baik (Muchlas, 2005:531).

\section{KAJIAN PUSTAKA DAN HIPOTESIS Kecerdasan Emosional}

Konsep kecerdasan emosional (emotional intelligence) terdiri atas dua kata, yaitu kecerdasan dan emosional. Kecerdasan dalam hal ini diartikan sebagai kemampuan individu untuk memahami secara cepat esensi suatu keadaan baru yang dihadapinya, sehingga mampu menyesuaikan diri dengan keadaan baru tersebut (Nawawi, 2006). Kecerdasan merupakan kemampuan individu dalam berfikir atau kemampuan memecahkan masalah. Kecerdasan juga diartikan sebagai kemampuan kualitas mental secara umum yang mencakup kemampuan belajar dari pengalaman, kemampuan menyesuaikan dengan situasi baru, dan kemampuan memahami konsep-konsep yang abstrak dan komplek. Kecerdasan secara umum merupakan suatu kapasitas individu dalam membangun cara berfikir, melakukan penalaran, dan memecahkan persoalan (Kreitner dan Kinicki, 2014). Konsep kecerdasan emosional menurut pendapat Cooper dan 
Syawaf (Nawawi, 2006) adalah kemampuan (ability) mengindera, memahami dan secara efektif menerapkan daya kepekaan emosi sebagai sumber engergi, informasi, koneksi, dn pengaruh yang manusiawi. Secara singkat, kecerdasan emosional adalah kemampuan menerapkan daya kepekaan emosi untuk mencapai keberhasilan dalam kehidupan bersama dengan orang lain.

\section{Motivasi Ekstrinsik}

Konsep motivasi berasal dari kata Latin movere yang artinya dorangan, sebab, atau alasan seseorang melakukan sesuatu. Dengan demikian motivasi berarti suatu kondisi yang mendorong atau menjadi sebab seseorang melakukan suatu perbuatan atau kegiatan (Nawawi, 2011). Motivasi merupakan proses psikologis yang meningkatkan dan mengarahkan perilaku untuk mencapai tujuan (Kreitner dan Kinicki, 2014). Mengacu pada konsep tersebut maka salah satu definisi motivasi adalah "proses yang dimulai dari defisiensi psikologis atau fisiologis yang menggerakkan perilaku atau dorongan yang ditujukan untuk mencapai tujuan atau memperoleh insentif" (Luthans, 2006). Definisi tersebut mengandung tiga kata kunci yaitu: defisiensi, dorongan, dan insentif. Defisiensi pada umumnya berupa suatu kebutuhan, yaitu suatu kondisi ketidakseimbangan baik secara fisiologis maupun psikologis. Dorongan merupakan tindakan yang bertujuan untuk mengurangi atau menghilangkan defisiensi atau kebutuhan yang ada. Insentif merupkan hasil tindakan yang dilakukan yang dapat mengurangi atau menghilangkan defisiensi atau kebutuhan.

\section{Budaya Organisasi}

Budaya secara harfiah berasal dari Bahasa Latin yaitu Colere yang memiliki arti mengerjakan tanah, mengolah, memelihara ladang (Soerjanto Poespowardojo, 1993). Menurut The American Herritage Dictionary mengartikan kebudayaan adalah sebagai suatu keseluruhan dari pola perilaku yang dikirimkan melalui kehidupan sosial, seniagama, kelembagaan, dan semua hasil kerja dan pemikiran manusia dari suatu kelompok manusia. Budaya organisasi adalah suatu nilai-nilai yang dipercayai menjadikarakteristik yang diberikan anggota kepada suatu organisasi. Budaya organisasi merupakan lingkungan internal suatu organisasi karena keberagaman budaya yang ada dalam suatu organisasi sama banyaknya dengan jumlah individu yang ada dalam organisasi tersebutsehingga budaya organisasi sebagai pemersatu budayabudaya yang ada pada diriuntuk menciptakan tindakan yang dpat diterima dalam organisasi. Budaya organisasi berarti suatu sistem nilai yang unik, keyakinan, dan norma-norma yang dimiliki secara bersama oleh anggota suatu organisasi. Budaya dapat menjadi suatu penyebab penting bagi keefektifan (Donnelly, Gibson, Ivancevich, 1996:41).

\section{Kreativitas Karyawan}

Eugene Raudsepp mengatakan kreativitas, bila didorong dan diarahkan dengan benar dapat menjadi aset terbesar perusahaan Anda. Kuncinya adlah suatu sikap yang luwes terhadap tatacara bisnis serta bakat-bakat karyawan (Timple, 2002). William D Ellis mengatakan kreativitas ditempat kerja adalah milik setiap orang dan banyak orang menemukan bahwa kreativitas dapat membuat hampir semua pekerjaan menjadi satu petualangan dari karier. Duduk bersandar dan memikirkan cara-cara baru mengerjakan segala sesuatu dapat terbayar (Timple, 2002). Sifat-sifat khas orang yang disebut kreatif: Sensitivitas terhadap lingkungan,

Fleksibel, terbuka, ingin tahu, dan selektif.

H1 : Kecerdasan Emosional secara parsial berperan positif terhadap Kreativitas Karyawan di Industri Perak Yogyakarta 
H2 : Motivasi Ekstrrensik secara parsial berperan positif terhadap Kreativitas Karyawan di Industri Perak Yogyakarta.

H3 : Budaya Organisasi secara parsial berperan positif terhadap Kreativitas Karyawan di Industri Perak Yogyakarta.

H4 : Kecerdasan Emosional, Motivasi Ekstrinsik dan Budaya Organisasi secara simultan berperan terhadap Kreativitas Karyawan di Industri Perak Yogyakarta.

\section{METODE PENELITIAN}

Penelitian ini dilakukan di kawasan industri perak di Kotagede, Yogyakarta yang dilaksanakan mulai tanggal 21-31 Desember 2015. Penelitian ini bersifat deskriptif dengan pendekatan penelitian kuantitatif. Data diperoleh dengan menyebarkan kuesioner terhadap karyawan di daerah Kotagede yang diambil sebagai sampel 60 karyawan. Untuk pengujian hipotesis, menggunakan analisis regresi berganda. Analisis ini memiliki tujuan untuk mengetahui pengaruh langsung terhadap hubungan variabel-variabel dalam penelitian. Dalam penelitian ini terdapat empat variabel, yaitu variabel dependen yang digunakan adalah kreativitas. Variabel independen terdiri dari kecerdasan emosional, motivasi ekstrinsik, budaya organisasi

Data hasil penelitian dianalisis dengan alat statistik yang terdiri dari uji validitas, uji reliabilitas, analisis deskriptif, uji asumsi klasik (uji normalitas, uji heterokedastisitas dan uji multikolinieritas), analisis regresi berganda, yang diolah dengan menggunakan SPSS 17.

\section{HASIL DAN PEMBAHASAN}

Hasil Analisis Koefesien Regresi Berganda

Coefficients $^{a}$

\begin{tabular}{|c|c|c|c|c|c|c|}
\hline \multirow[b]{2}{*}{ Model } & & \multicolumn{2}{|c|}{$\begin{array}{l}\text { Unstandardized } \\
\text { Coefficients }\end{array}$} & \multicolumn{2}{|c|}{$\begin{array}{l}\text { Standardized } \\
\text { Coefficients }\end{array}$} & \multirow[b]{2}{*}{ Sig. } \\
\hline & & B & Std. Error & Beta & $\mathrm{t}$ & \\
\hline \multirow[t]{4}{*}{1} & (Constant) & .466 & 5.082 & & .092 & .997 \\
\hline & $\mathrm{X} 1$ & .413 & .067 & .608 & 6.197 & .000 \\
\hline & $\mathrm{X} 2$ & .154 & .61 & .213 & 2.027 & .019 \\
\hline & $\mathrm{X} 3$ & .179 & .083 & .227 & 2.152 & .036 \\
\hline
\end{tabular}

a. Dependent Variable: Y

Hasil dari penelitian ini diketahui bahwa variabel independen mempengaruhi variabel dependen sebesar 0,645, dapat diartikan bahwa variabel dependen X1 (Kecerdasan Emosional), X2 (Motivasi Ekstrinsik), dan X3 (Budaya Organisasi) yang dimiliki mempengaruhi variabel dependen Y (Kreativitas) sebesar 64,5\%. Hal ini menunjukkan bahwa masih ada faktor-faktor lain yang mempengaruhi kreativitas karyawan pada Asosiasi Industri Kerajinan Perak di Kotagede Yogyakarta sebesar 35,5\%.

Selain itu dengan melihat tabel coefficients kita dapat mengetahui hasil regresi berganda dalam bentuk persamaan yaitu : $\mathrm{Y}=0.608 \mathrm{X} 1+0.103 \mathrm{X} 2+0,227 \mathrm{X} 3+\mathrm{e}$. Yang berarti bahwa variabel independen X1 (Kecerdasan Emosional) mempengaruhi Y (Kreativitas) sebesar 0,608, variabel X2 (Motivasi Ekstrinsik) mempengaruhi Y (Kreativitas) sebesar 0,213. X3 (Budaya 
Organisasi mempengaruhi Y (Kreativitas) sebesar 0,227. Untuk menjawab permasalahan yang ada dapat diketahui hasil dari analisis sebagai berikut:

Hasil uji hipotesis 1 berdasarkan tabel (uji t) menunjukkan bahwa tingkat signifikansi variabel kecerdasan emosional sebesar 0,000 lebih kecil dari 0,05 sehingga kecerdasan emosional berpengaruh terhadap kreatifitas karyawan/pengrajin perak. Dengan demikian, semakin tinggi tingkat kecerdasan emosional karyawan/pengrajin lebih baik pula tingkat kreatifitas yang dimiliki, sedangkan semakin rendah tingkat kecerdasan emosional karyawan/pengrajin maka semakin rendah pula tingkat kreativitas yang dimiliki.

Hasil uji hipotesis 2 berdasarkan tabel (uji t) menunjukkan bahwa tingkat signifikansi variabel motivasi ekstrinsik sebesar 0.019 lebih kecil dari 0,05 sehingga motivasi ekstrinsik berpengaruh terhadap kreatifitas karyawan/pengrajin perak. Dengan demikian, semakin tinggi motivasi ekstrinsik yang ada lebih baik pula tingkat kreatifitas yang dimiliki karyawan/pengrajin, sedangkan semakin rendah motivasi ekstrinsik yang ada maka semakin rendah pula tingkat kreativitas yang dimiliki karyawan/pengrajin.

Hasil uji hipotesis 3 berdasarkan tabel (uji t) menunjukkan bahwa tingkat signifikansi variabel budaya organisasi sebesar 0.036 lebih kecil dari 0,05 sehingga budaya organisasi berpengaruh terhadap kreatifitas karyawan/pengrajin. Dengan demikian, semakin baik budaya organisasi lebih baik pula tingkat kreatifitas yang dimiliki, sedangkan semakin buruk budaya organisasi maka semakin rendah pula tingkat kreativitas yang dimiliki karyawan/pengrajin.

Hasil Uji Hipotesis 4 pengaruh variabel independen X1 (Kecerdasan Emosional), X2 (Motivasi Ekstrinsik), dan X3 (Budaya Organisasi) terhadap variabel dependen Y (Kreativitas). Hasil uji hipotesis 4 dapat dilihat pada tabel diatas, nilai $\mathrm{F}$ diperoleh sebesar 34.379 dengan tingkat kesalahan 5\%, dimana $\mathrm{F}$ tabel $=3,11$ ternyata $\mathrm{F}$ hitung $>\mathrm{F}$ tabel $(34.379>3,11)$, dengan demikian $\mathrm{F}$ hitung $>\mathrm{F}$ tabel sehingga $\mathrm{HO}$ ditolak dan Ha diterima, ini menunjukkan bahwa secara simultan antara variabel independen X1 (Kecerdasan Emosional), X2 (Motivasi Ekstrinsik), dan X3 (Budaya Organisasi) berpengaruh terhadap variabel dependen Y (Kreativitas)

\section{PENUTUP}

Berdasarkan analisis data dan hasil pengujian hipotesis pada penelitian ini dapat disimpulkan bahwa kecerdasan emosional karyawan berpengaruh positif terhadap kreativitas karyawan dengan tingkat signifikansi 0,000. Motivasi ekstrinsik berpengaruh positif terhadap kreativitas karyawan dengan tingkat signifikansi 0,019. Budaya organisasi berpengaruh positif terhadap kreativitas karyawan dengan tingkat signifikansi 0,036. Dan Secara simultan variabel kecerdasan emosional, motivasi ekstrinsik, dan budaya organisasi berpengarut positif terhadap kreatifitas dengan nilai $F$ diperoleh sebesar 34.379 dengan tingkat kesalahan 5\%, Kemampuan persamaan regresi dalam penelitian ini, untuk menjelaskan besarnya variasi yang terjadi pada variabel terikat sebesar 64,5\% sementara 35.5\% dijelaskan oleh variabel yang tidak dapat dijelaskan peneliti.

\section{DAFTAR PUSTAKA}

Azwar, S. 2007. Metode Penelitian. Pustaka Pelajar, Yogyakarta.

Cheung, M.F.Y, and Wong, C.S. (2011). Transformational Leadership,Leader Support, And Employee Creativity.Leadership \& OrganizationDevelopment Journal, Vol. 32 No. 7.

Felix. 2014. Pengaruh Sosialisasi Pemerintah dan Kepeminpinan Lurah Terhadap Kesadaran Masyarakat Membayar Pajak Bumi dan Bangunan di Kelurahan Sendangsari, Pajangan, 
Bantul, Daerah Istimewa Yogyakarta. Yogyakarta : Fakultas Ekonomi Universitas Sarjanawiyata Tamansiswa.

Ghozali, I. 2007. Aplikasi Analisis Multivariate dengan Program SPSS. Badan Penerbit Univeristas Diponegoro, Semarang.

Greenberg J. and Baron R.A. 2003. Behavior in Organizations. Eighth Edition, Prentice Hall, Pearson Education International, Australia.

Handoko, T. H. 2001. Manajemen Personalia \& Sumberdaya Manusia. Edisi Kedua, BPFE Universitas Gadjah Mada, Yogyakarta.

Hasibuan Malayu, 2012, Manajemen Sumber Daya Manusia, edisi revisi. Jakarta: Bumi Perkasa.

Hasibuan, M.S.P. 2010. Manajemen Sumber Daya Manusia. Edisi Revisi. Cetakan Keempatbelas. Jakarta: Bumi Aksara.

Hasibuan, M.S.P. 2010. Organisasi dan Motivasi: Dasar Peningkatan Produktivitas. Cetakan Ketujuh. Jakarta: Bumi Aksara.

Herawati, Jajuk dkk. 2015. Pengaruh Kecerdasan Emosional, Motivasi Ekstrinsik, dan Kepemimpinan Transformasional Terhadap Kreativitas Karyawan Pada Industri Kerajinan Perak Di Kota Yogyakarta Tahun 2015. Yogyakarta: Penelitian DIPA KOPERTIS V Yogyakarta, Fakultas Ekonomi Universitas Sarjanawiyata Tamansiswa.

Herry Mardianto. 2010. Sejarah Kerajinan Perak Kota Gede. Artikel: https://tokoperakonline.wordpress.com

Jogiyanto. 2008. Metodologi Penelitian Sistem Informasi. Yogyakarta: Penerbit Andi.

Kartowagiran, Badrun. 2009. Pengembangan Instrumrn Kinerja SMK-SBI. Dosen Pascasarjana dan Fakultas Teknik. Universitas Negeri Yogyakarta.

Khalid, S. and Zubair, A. (2014). Emotional Intelligence, Self-Efficacy, and Creativity Among Employees of Advertising Agencies. Pakistan Journal of Psychological Research, 2014, Vol. 29, No. 2, 203-221.

Kreitner, R. dan Kinicki, A. 2005. Perilaku Organisasi. Edisi Kelima, Buku 2, Salemba Empat, Jakarta.

Kreitner, R. dan Kinicki, A. 2014. Perilaku Organisasi. Edisi Kesembilan. Buku 1. Alih Bahasa: Biro Bahasa Alkemis. Jakarta: Salemba Empat.

Kusdi. 2011. Budaya Organisasi Teori, Penelitian dan Praktik. Jakarta : Salemba Empat.

Laird D McLean. 2005. Organizational Culture's Influence on Creativity and Innovation: A Review of the Literature and Implications for Human Resource Development. Journal : Advances in Developing Human Resources, Vol. 7, No. 2, PP. 226-246, 2005.

Luthans, F. 2006. Perilaku Organisasi. Edisi Kesepuluh. Andi Offset, Yogyakarta.

Muchlas, Makmuri. 2005. Perilaku Organisasi. Yogyakarta : Gajah Mada University Press, Munandar, A.S. 2001. Psikologi Industri dan Organisasi. UI Press, Jakarta.

Nawawi, H. 2003. Kepemimpinan Mengefektifkan Organisasi. Gadjah Mada University Press, Yogyakarta.

Nawawi, H. dan Hadari, M. 2004. Kepemimpinan Yang Efektif. Gadjah Mada University Press, Yogyakarta.

Robbins S. P. 2003, Organzation Behavior. New Jersey : Prentice Hall International, Inc

Robbins, S.P, dan Judge, T.A. 2015. Perilaku Organisasi. Edisi Keenambelas. Buku 1, Alih Bahasa: Ratna Saraswati dan Febriella Sirait. Jakarta: Penerbit Salemba Empat.

Sekaran, U., 2003, Research Methods for Business: A Skill Building Approach. Fourth Edition, John Willey dan Sons, New York. 
Siagian, S.P. 2012. Teori Motivasi dan Aplikasinya. Cetakan Keempat. Jakarta: Penerbit Rineka Cipta.

Soerjanto Poespowardojo. 1993. Pembangunan Nasional dalam Perspektif Budaya Sebuah Pendekatan Filsafat. Jakarta : Grasindo.

Sudjana. 2003. Teknik Analisis Korelasi dan Regresi bagi Para Peneliti. Bandung: Tarsito.

Sugiyono. 2006. Metode Penelitian Bisnis. Alfabeta. Bandung.

Sugiyono. 2010. Metode Penelitian Administrasi. Alfabeta, Bandung.

Supardi. 2006. Metodologi Penelitian. Mataram : Yayasan Cerdas Press.

Sutopo. 2006. Metode Penelitian Kuantitatif. Surakarta : UNS Press.

Tampubolon, Manahan. 2004. Perilaku Keorganisasian. Jakarta : Ghalia Indonesia.

Tan, Victor S.L. 2002. Changing Your Corporate Culture. Singapore, San Times Books International.

Taniredja, dkk. 2011. Penelitian Kuantitatif. Bandung : Alfabeta

Taufiq Hidayat. 2012. Kerajinan Perak Kotagede. Artikel : http://kotagede.blogspot.com.

Timpe, Dile 2002. Kreativitas. Jakarta : PT. Gramedia

Wibowo, S.E,. M. Phil. 2013. Budaya Organisasi Sebuah Kebutuhan Untuk Meningkatkan Kinerja Jangka Panjang. Jakarta : PT Raja Grafindo Persada.

Wirawan. 2007. Budaya dan Iklim Organisasi Teori Aplikasi dan Penelitian. Jakarta : Salemba Empat

Wiyono, Gendro. 2011. Merancang Penelitian Bisnis, Dengan Alat Analisis SPSS 17.0 \& SmartPLS 2.0. Yogyakarta: UPP STIM YKPN

Yukl, G. 2005. Kepemimpinan Dalam Organisasi. Edisi Kelima, Indeks, Jakarta.

Zhang, X., Bartol, K.M. (2010). Linking Empowering Leadership and Employee Creativity: The Influence Of Psychological Empowerment, Intrinsic Motivation, and Creative Process Engagement. Academy of Management Journal, Vol. 53, No. 1, 107-128. 